\title{
Cascaded Model Predictive Speed Control of a Permanent Magnet Synchronous Machine
}

\author{
Cristian Garcia and Cesar Silva \\ Dept. of Electronics Engineering \\ Universidad Tecnica Federico Santa Maria \\ Valparaiso, Chile \\ cristian.garciap@alumnos.usm.cl
}

\author{
Jose Rodriguez \\ Dept. of Engineering \\ Universidad Andres Bello \\ Santiago, Chile \\ jose.rodriguez@unab.cl
}

\author{
Pericle Zanchetta \\ Dept. of Elec. and Electron. Eng. \\ University of Nottingham \\ Nottingham, UK \\ pericle.zanchetta@nottingham.ac.uk
}

\begin{abstract}
This paper proposes a model predictive speed control of a permanent magnet synchronous machine (PMSM). The control scheme has a cascade architecture, where the inner loop uses a finite set model predictive control scheme (FS-MPC) for the electrical subsystem, and the outer loop uses a dead-beat model predictive control for the mechanical subsystem. Due to the discrete nature of the control platform an accurate discrete model of the systems is necessary. In this work both systems, electrical and mechanical, are discretizated with a second order Taylor method. Simulation results are presented to validate the proposed control strategy.
\end{abstract}

Index Terms-Model Predictive Control, variable speed drives, dead-beat control.

\section{INTRODUCTION}

Permanent magnet synchronous machines (PMSM) are widely employed for applications such as servo control [1], [2], wind power [3], [4] and electric traction [5], [6], due to their high power density and efficiency. The most popular control methods for PMSM are the field oriented control [7] and direct-torque control [8].

Model predictive control (MPC) has gained importance thanks to the powerful breakthrough in microprocessors technology. The basic principle of operation is the calculation of the future behavior of the system in order to optimize its performance. MPC has been implemented successfully in multiple power electronics applications such as in neutral point clamped converters (NPC) [9], cascade H-bridge converters (CHB) [10], flying capacitors converters [11], three-phase two-level inverter [12], multilevel converters [13], matrix converters [14] and many others.

Model predictive control of electrical drives has been proposed in [15]-[17]. However, these works used the MPC only for the control of the internal electric subsystem, while the speed is controlled by a PI controller, i.e. not making full use of the dynamic performance of the inner MPC control.

On the other hand, there are works that have proposed a complete model predictive control of the speed in a permanent magnet synchronous machine [18]-[20] and also for permanent magnet brushless dc machines [21]. These have a centralized architecture, using finite set model predictive control (FS-MPC). These included all the control objective in a complex cost function, with many significant weighting factors which are determined heuristically and which may become difficult to tune [22].

This paper proposes a intermediate solution using a cascaded speed predictive control for a PMSM based on the dynamic model of the mechanical subsystem and using FS-MPC for the control of the electrical subsystems. The different time constant between the electrical and mechanical subsystems, allows to downsample the outer speed loop. Under this consideration, the fast FS-MPC internal loop becomes almost ideal to the outer speed loop, allowing to have an independent speed controller design using simple and physically insightful predictive control approach. The inner control has a simple cost function with only two objective terms for the tracking of quadrature and direct stator currents, and without weight factors. The outer speed loop controller is implemented by means of inversion of the mechanical subsystem model to determine the electric torque reference that allows the tracking of the reference speed with dead-beat performance, although at a subsampled rate. To achieve the mechanical model inversion, knowledge of the load torque is requires. For this reason, a disturbance observer implemented in the form of a Kalman filter (KF) is used. Also, the compensation of the estimated load torque allows to achieve zero steady state error in the speed tracking even without integration in the controller.

\section{DRIVE MODEL}

The cascaded predictive speed control strategy is implemented for a PMSM fed by a two level voltage source inverter (2L-VSI). This section presents a mathematical model of the power converter and the electrical machine.

\section{A. Power Converter}

The 2L-VSI is the most common power converter in medium and low power rate drive applications. The converter generates the voltage to feed the stator of the machine, as shown in Fig. 1(a). The 2L-VSI generates eight voltage vectors, six active vectors and two zero vectors (Fig. 1(b)).

The voltage vector of the power converter in a stationary $\alpha \beta$-frame is,

$$
\mathbf{v}_{s_{\alpha \beta}}=V_{d c} \cdot \frac{2}{3}\left[1 e^{j \frac{2 \pi}{3}} e^{j \frac{\pi}{4 \pi}}\right] \cdot \mathbf{S},
$$




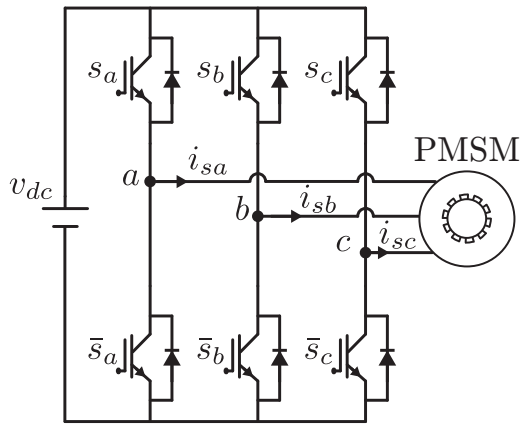

(a)

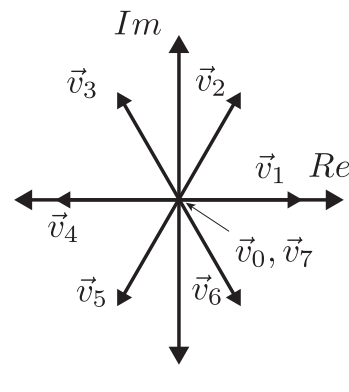

(b)
Fig. 1. Two level voltage source inverter (2L-VSI). (a) Power circuit; (b) Voltage vectors.

where $V_{d c}$ is the dc-link voltage and $\mathbf{S}=\left[S_{a} S_{b} S_{c}\right]^{T}$ are the switching state of the converter.

Then, the power converter voltage in a synchronous $d q$ frame oriented with the rotor angle of the PMSM $\theta_{r}$ is,

$$
\mathbf{v}_{s}=\mathbf{v}_{s^{\alpha \beta}} \cdot e^{-j \theta_{r}}
$$

\section{B. Permanent Magnet Synchronous Machine}

The model of the PMSM in a synchronous $d q$-frame oriented with the rotor position angle $\theta_{r}$ is the following,

$$
\dot{\mathbf{x}}=f(\mathbf{x}, \mathbf{u}),
$$

where,

$$
f(\cdot)=\left(\begin{array}{c}
-\frac{R}{L_{s}^{s}} i_{s d}+\omega_{r} i_{s q}+\frac{1}{L_{s}} v_{s d} \\
-\omega_{r} i_{s d}-\frac{R_{s}}{L_{s}} i_{s q}-\frac{\psi_{m}}{L_{s}} \omega_{r}+\frac{1}{L_{s}} v_{s q} \\
\frac{3}{2 J_{m}} \psi_{m} p^{2} i_{s q}-\frac{B_{m}}{J_{m}} \omega_{r} \\
\omega_{r}
\end{array}\right)
$$

and,

$$
\begin{aligned}
& \mathbf{x}=\left[\begin{array}{llll}
i_{s d} & i_{s q} & \omega_{r} & \theta_{r}
\end{array}\right]^{T}, \\
& \mathbf{u}=\left[\begin{array}{ll}
v_{s d} & v_{s q}
\end{array}\right]^{T} .
\end{aligned}
$$

The parameters of the machine are $R_{s}$ stator resistor, $L_{s}$ stator inductance, $\psi_{m}$ the magnitude of the flux generated by the rotor magnet, $p$ number of poles, $J_{m}$ inertia and $B_{m}$ the friction of the machine. The values of these parameters are shown in the Table I.

\section{Control Strategy}

The block scheme of the control strategy for a PMSM proposed in this work is shown in the Fig. 2. The control scheme has a cascaded structure composed by an internal and external control loop. In this section, both control loop are described and analyzed independently.

\section{A. Inner Control Loop}

The inner control loop corresponds to the electrical system control of the machine. Here, a Finite Set Model Predictive Control (FS-MPC) is used to track the quadrature and direct current references that are generated for the external loop.

Due to the discrete nature of the control platform and for the fact that FS-MPC needs predictions of the control states at the next sample, a discrete model of the machine is needed. Using the continuous model of the PMSM, presented in (3)(4), and a second order Taylor discretization, the following discrete model is obtained,

$$
\mathbf{x}^{k+1}=\mathbf{x}^{k}+\left.T_{s} \cdot \dot{\mathbf{x}}\right|_{k}+\frac{T_{s}^{2}}{2} \cdot \ddot{\mathbf{x}}_{\mid k}
$$

where $T_{s}$ is sampling period of the inner control loop.

First order discretization methods introduce significant modeling error at high frequencies [23]. Being Model Predictive Control a strategy of high bandwidth, this errors deteriorate the quality of the control. For this reason, a second order Taylor approximation that reduce this error is used in this work for the electrical as well as mechanical subsystem.

The FS-MPC has two objectives:

- To obtain maximum torque for ampere of the machine. This objective is achieved with a zero direct current references.

- A good tracking of the quadrature current of the machine.

The cost function that can achieve both objectives is the following,

$$
g=\left(\hat{i}_{s d}^{k+2}\right)^{2}+\left(i_{s q}^{*}-\hat{i}_{s q}^{k+2}\right)^{2} .
$$

The equation (6) is evaluated for the eight vectors of the power converter. The voltage vector that minimizes the cost function is selected and applied in the next sampling period.

\section{B. Outer Control Loop}

The outer loop corresponds to the control of the mechanical subsystem of the machine. The objective is to achieve a good tracking of the speed reference with a high dynamic response. The predictive approach used is a dead-beat control. This controller uses a mechanical equation to obtain a quadrature stator current reference (proportional to the electrical torque). The following mechanical equation is considered:

$$
J_{m} \frac{d \omega_{m}}{d t}=T_{e}-T_{L}-B_{m} \omega_{m},
$$

where $\omega_{m}$ is the mechanical speed, $T_{e}$ is the electrical torque of the PMSM and $T_{L}$ is the load torque. The electrical torque of the machine is,

$$
T_{e}=\frac{3}{2} p \psi_{m} \cdot i_{s q}
$$

Replacing the (8) in (7) and then solving for the speed derivative:

$$
\frac{d \omega_{m}}{d t}=\frac{3}{2 J_{m}} p \psi_{m} \cdot i_{s q}-\frac{1}{J_{m}} T_{L}-\frac{B_{m}}{J_{m}} \omega_{m} .
$$




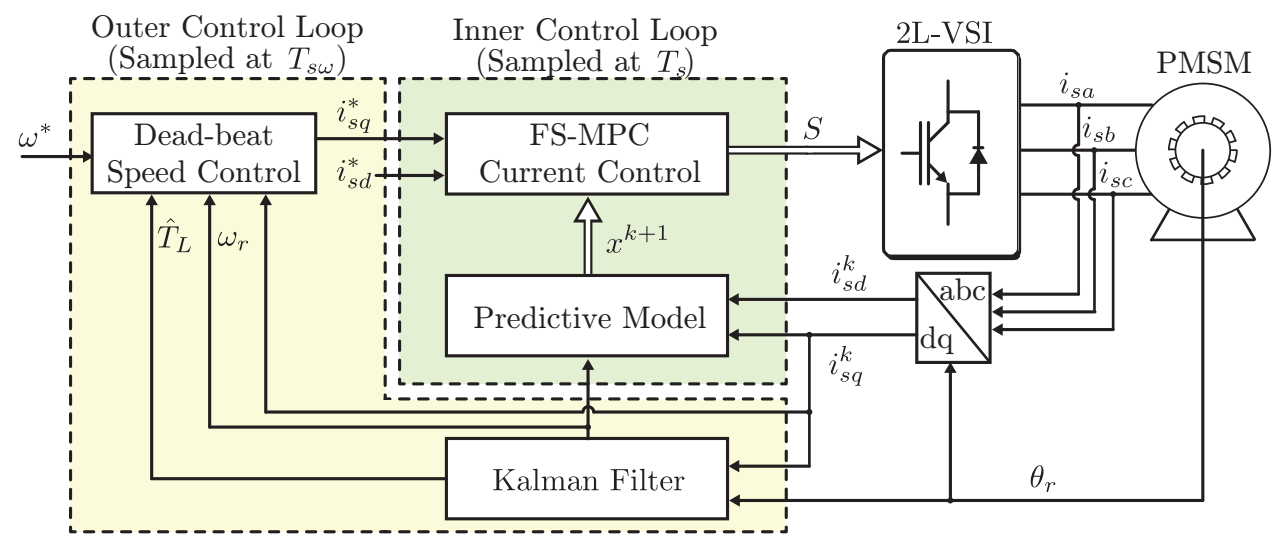

Fig. 2. Scheme of Predictive Speed Control of a PMSM.

The second order derivative of the speed is obtained by derivation of equation (9),

$$
\frac{d^{2} \omega_{m}}{d t^{2}}=\frac{3}{2 J_{m}} p \psi_{m} \frac{d i_{s q}}{d t}-\frac{B_{m}}{J_{m}} d \omega_{\underline{m}} .
$$

The second order Taylor discretization of the mechanical speed is then considered:

$$
\omega_{m}^{k+1}=\omega_{m}^{k}+\left.T_{s \omega} \cdot \dot{\omega}_{m}\right|_{k}+\frac{T_{s \omega}^{2}}{2} \cdot \ddot{\omega}_{m} \mid k,
$$

where the $T_{s \omega}$ is the downsampling period of the outer control loop. The derivative of the quadrature stator current in (10) is discretized with the forward-Euler method:

$$
\frac{d i_{s q}}{d t}=\frac{i_{s q}^{k+1}-i_{s q}^{k}}{T_{s \omega}} .
$$

Then, using equations (9), (10) and (12) in equation (11) and considering $\omega_{m}^{k+1}=\omega^{*}$ and $i_{s q}^{k+1}=i_{s q}^{*}$, where $\omega^{*}$ and $1_{s q}^{*}$ are the speed and quadrature current references respectively, it is possible to solve equation (11) in order to obtain a quadrature stator current reference:

$$
\begin{aligned}
i_{s q}^{*}= & -\frac{1}{\left(J_{m}^{2} K_{T} T_{s \omega}\right)}\left(2 J^{2} \omega_{m}^{k}-2 J_{m}^{2} \omega^{*}+B_{m}^{2} T_{s \omega}^{2} \omega_{m}^{k}\right. \\
& +B_{m} \hat{T}_{L} T_{s \omega}^{2} p-2 B_{m} J_{m} T_{s \omega} \omega_{m}^{k}-2 J_{m} \hat{T}_{L} T_{s \omega} p \\
& \left.+i_{s q}^{k} J_{m}^{2} K_{T} T_{s \omega}-B_{m} i_{s q}^{k} J_{m} K_{T} T_{s w}^{2}\right),
\end{aligned}
$$

where the constant $K_{T}=\frac{3 p^{2}}{2} \frac{\psi}{m}_{m}$.

The reference obtained in the last equation is used in the inner model predictive current control (6). Equation (13) needs a load torque $\hat{T}_{L}$. for this reason a disturbance observer is implemented to estimate $\hat{T}_{L}$ in the form of a Kalman filter. Details of this Kalman filter implementation were reported the the same authors in [24].

\section{Simulation Result}

The simulations of this work were performed using the software PLECS. The inner control loop runs at a sampling time of $T_{s}=40[\mu \mathrm{s}]$, while the outer speed loop it is subsampled by a factor of ten, i.e. $T_{s \omega}=400[\mu s]$. The
TABLE I

PARAMETERS

\begin{tabular}{c|cc} 
Parameter & Value & Unit \\
\hline \hline$R_{s}$ & 0.369 & {$[\Omega]$} \\
$L_{s}$ & 2.4 & {$[\mathrm{mH}]$} \\
$\psi_{m}$ & 0.129 & {$[\mathrm{~Wb}]$} \\
$J_{m}$ & $1.916 \cdot 10^{-3}$ & {$\left[\mathrm{Kg} \cdot \mathrm{m}^{2}\right]$} \\
$B_{m}$ & $4.64 \cdot 10^{-3}$ & {$\left[\mathrm{Nm} \cdot \frac{\mathrm{rad}}{\mathrm{s}}\right]$} \\
$p$ & 5 & \\
\hline$T_{s}$ & 40 & {$[\mu s]$} \\
$T_{s \omega}$ & 400 & {$[\mu s]$}
\end{tabular}

parameters of the permanent magnet synchronous machine are given in Table I.

The dynamic behavior of the proposed control scheme for the PMSM is presented in Fig. 3. The maneuver consist in: start with zero speed reference, at time $t=0.02[s]$ the speed reference changes to nominal value, then at time $t=0.07[s]$ a nominal load torque is applied, and finally at $t=0.12[s]$ a speed reversal from the nominal speed to negative nominal speed rate is applied. The speed control of the machine shows good reference tracking, with a fast dynamic response and without observable overshoot or undershoots. The quadrature stator current is shown in Fig. 3(b). The reference of this current is produced by the outer control loop (dead-beat control) and it is tracked by the inner control loop (FS-MPC). Fig. 3(c) shows the good tracking of the direct quadrature current, which is permanent set to zero. The $a$-phase stator current of the PMSM is shown in Fig. 3(d) illustrating that the phase current are highly sinusoidal, despite the variable switching frequency.

Fig. 4 shows the steady-state behavior of the control of the machine at nominal speed and nominal load torque. The control of the speed is stable around of the reference, without offset. Despite the fact that the speed control is proportional in nature. The inner current controllers for the quadrature and direct stator currents have a steady-state tracking of the reference. The phase stator current (Fig. 4(d)) has a sinusoidal shape.

A load impact is shown in the Fig. 5 where, in the time 

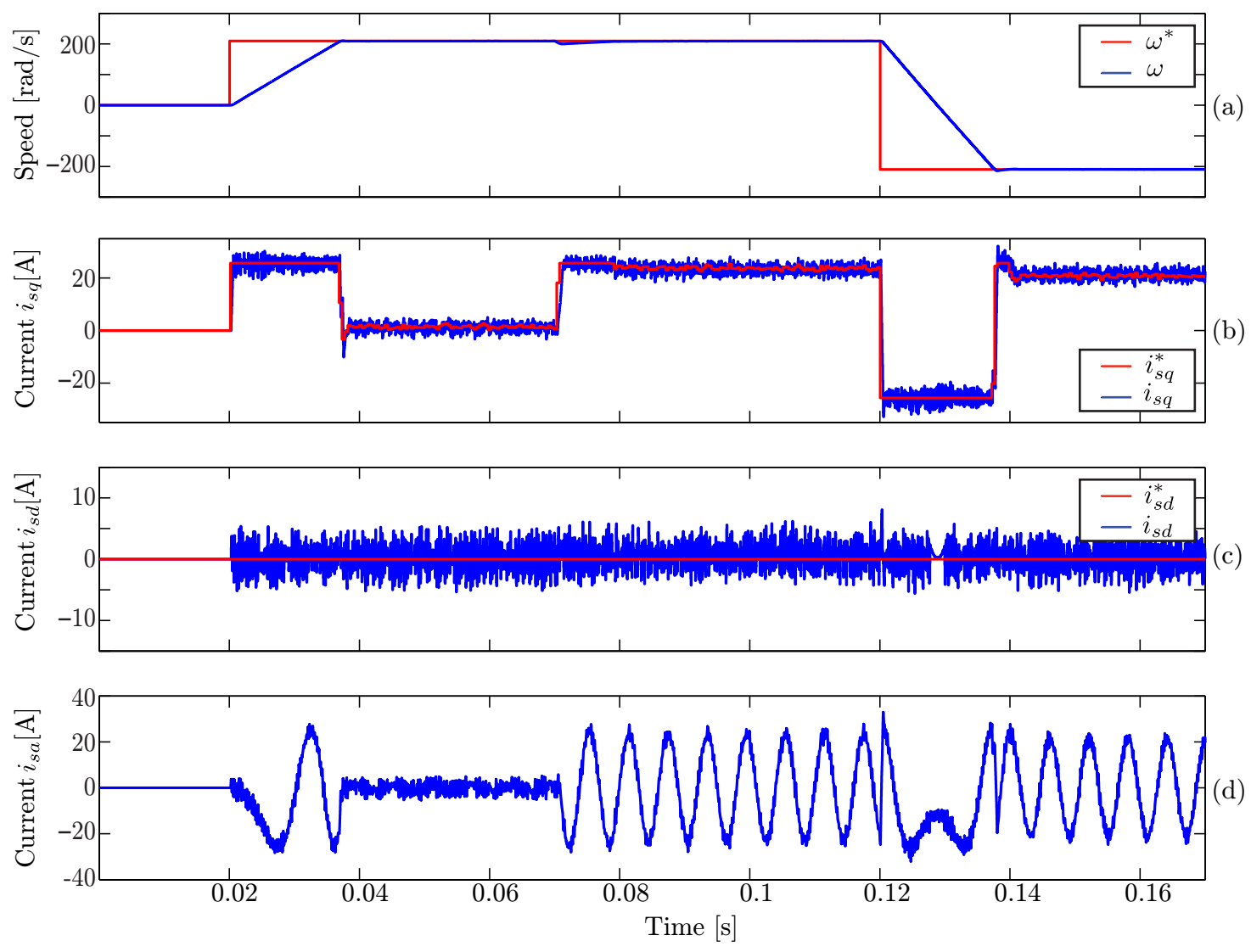

Fig. 3. Dynamic response. (a) motor speed; (b) Quadrature stator current; (c) Direct stator current; (c) Phase stator current.

$t=0.005[s]$, a nominal load torque is applied. This result show a fast disturbance rejection without steady-state error, thanks to the load torque disturbance and dead-beat control considers.

\section{Conclusions}

This paper presented a speed model predictive control for a permanent magnet synchronous machine. The strategy used a cascade architecture similarly to a well-know field oriented control or direct torque control. The predictive control proposed uses the optimal response of current FSMPC loop to decouple its dynamics form to the outer loop design. This allows for dead-beat design of the outer loop, provided that a reasonable downsampling time is used in the external loop.

The technique proposes for the PMSM is validated with simulation results. The dynamics and steady-state behavior of the results show a good performance of the machine. The speed control has high dynamic performance respect to changes in the speed reference and torque disturbance. The steady-state response is also good, without steady-state error despite not integration in the controller, thanks to the use of a load torque observer.

\section{ACKNOWLEDGMENT}

This work was supported in part by the Advanced Center for Electrical and Electronic Engineering, AC3E, Basal
Project FB0008, in part by CCTVal (FB0821) and in part by the Fondecyt 1150829. Furthermore, CONICYT Scholarships supported the work of C. Garcia for PhD studies (21130140).

\section{REFERENCES}

[1] W. Yu, Y. Chen, Y. Luo, and Y. Pi, "Frequency domain modelling and control of fractional-order system for permanent magnet synchronous motor velocity servo system," IET Control Theory \& Applications, vol. 10, no. 2, pp. 136-143, jan 2016.

[2] H. Liu and S. Li, "Speed Control for PMSM Servo System Using Predictive Functional Control and Extended State Observer," IEEE Transactions on Industrial Electronics, vol. 59, no. 2, pp. 1171-1183, feb 2012.

[3] J. Hui, A. Bakhshai, and P. Jain, "An Energy Management Scheme with Power Limit Capability and an Adaptive Maximum Power Point Tracking for Small Standalone PMSG Wind Energy Systems," IEEE Transactions on Power Electronics, vol. 31, no. 7, pp. 1-1, 2015.

[4] J. Lee and Y.-S. Kim, "Sensorless fuzzy-logic-based maximum power point tracking control for a small-scale wind power generation systems with a switched-mode rectifier," IET Renewable Power Generation, vol. 10, no. 2, pp. 194-202, feb 2016.

[5] F. Mwasilu and J.-W. Jung, "Enhanced Fault-Tolerant Control of Interior PMSMs Based on an Adaptive EKF for EV Traction Applications,' IEEE Transactions on Power Electronics, vol. 31, no. 8, pp. 5746-5758, aug 2016.

[6] E. Mese, Y. Yasa, H. Akca, M. G. Aydeniz, and M. Garip, "Investigating Operating Modes and Converter Options of Dual Winding Permanent Magnet Synchronous Machines for Hybrid Electric Vehicles," IEEE Transactions on Energy Conversion, vol. 30, no. 1, pp. 285-295, mar 2015 .

[7] Z. Wang, J. Chen, M. Cheng, and K. T. Chau, "Field-Oriented Control and Direct Torque Control for Paralleled VSIs Fed PMSM Drives 

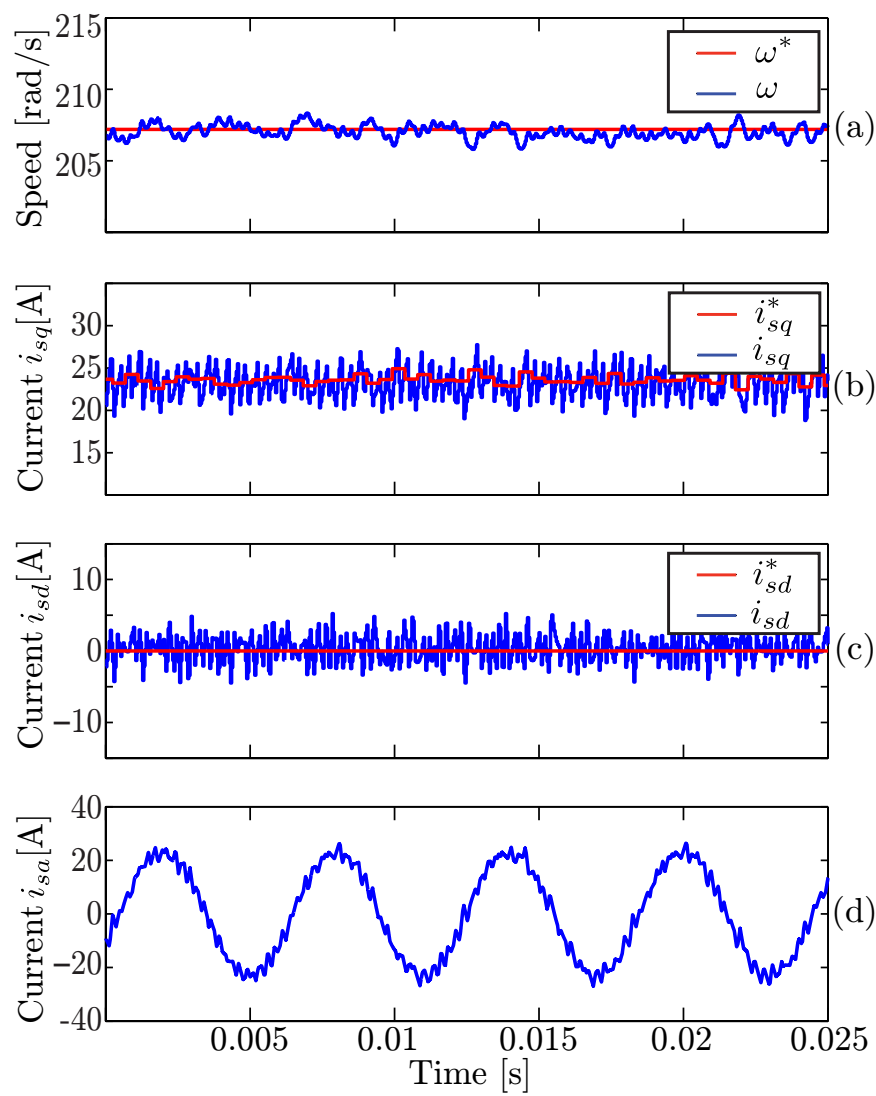

Fig. 4. Steady state. (a) motor speed; (b) Quadrature stator current; (c) Direct stator current; (c) Phase stator current.

With Variable Switching Frequencies," IEEE Transactions on Power Electronics, vol. 31, no. 3, pp. 2417-2428, mar 2016.

[8] F. Niu, K. Li, B. Wang, and E. G. Strangas, "Comparative evaluation of direct torque control strategies for permanent magnet synchronous machines," in 2014 IEEE Applied Power Electronics Conference and Exposition - APEC 2014. IEEE, mar 2014, pp. 2438-2445.

[9] T. Laczynski and A. Mertens, "Predictive stator current control for medium voltage drives with lc filters," Power Electronics, IEEE Transactions on, vol. 24, no. 11, pp. 2427-2435, 2009.

[10] P. Cortes, A. Wilson, S. Kouro, J. Rodriguez, and H. Abu-Rub, "Model predictive control of multilevel cascaded h-bridge inverters," Industrial Electronics, IEEE Transactions on, vol. 57, no. 8, pp. 2691-2699, 2010.

[11] F. Defay, A.-M. Llor, and M. Fadel, "Direct control strategy for a fourlevel three-phase flying-capacitor inverter," Industrial Electronics, IEEE Transactions on, vol. 57, no. 7, pp. 2240-2248, 2010.

[12] J. Rodriguez, M. P. Kazmierkowski, J. R. Espinoza, P. Zanchetta, H. Abu-Rub, H. A. Young, and C. A. Rojas, "State of the Art of Finite Control Set Model Predictive Control in Power Electronics," IEEE Transactions on Industrial Informatics, vol. 9, no. 2, pp. 10031016, May 2013.

[13] T. Geyer and S. Mastellone, "Model predictive direct torque control of a five-level ANPC converter drive system," in 2011 IEEE Energy Conversion Congress and Exposition. IEEE, Sep. 2011, pp. 363-370.

[14] C. Garcia, M. Rivera, M. Lopez, J. Rodriguez, R. Pena, P. Wheeler, and J. Espinoza, "A Simple Current Control Strategy for a Four-Leg Indirect Matrix Converter,' IEEE Transactions on Power Electronics, vol. PP, no. 99, pp. 1-1, 2014.

[15] Z. Zheng, K. Wang, and Y. Li, "A novel motor controller based on model predictive control," in 2013 15th European Conference on Power Electronics and Applications (EPE). IEEE, Sep. 2013, pp. 1-9.

[16] J. Guzinski and H. Abu-Rub, "Speed Sensorless Induction Motor Drive With Predictive Current Controller," IEEE Transactions on Industrial Electronics, vol. 60, no. 2, pp. 699-709, Feb. 2013.
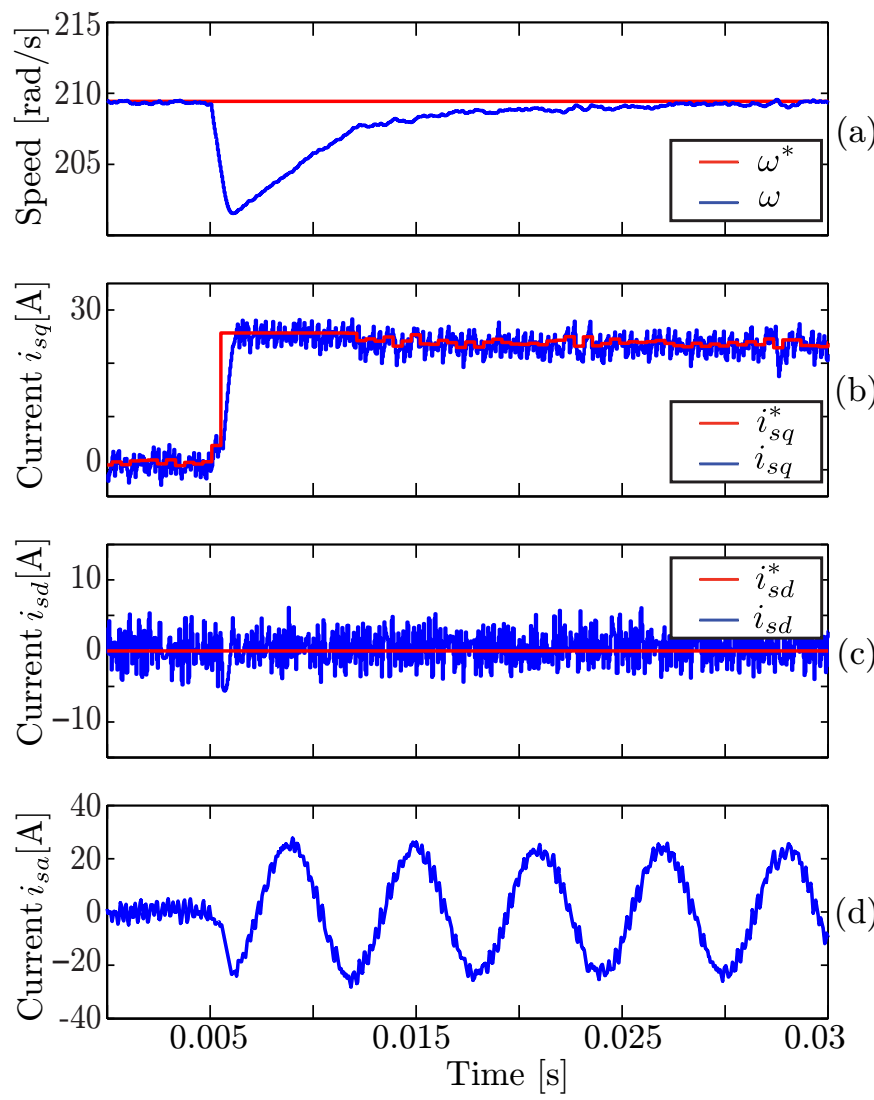

Fig. 5. Load impact response. (a) motor speed; (b) Quadrature stator current; (c) Direct stator current; (c) Phase stator current.

[17] T. Geyer, "Model Predictive Direct Current Control: Formulation of the Stator Current Bounds and the Concept of the Switching Horizon," IEEE Industry Applications Magazine, vol. 18, no. 2, pp. 47-59, Mar. 2012.

[18] E. Fuentes and R. M. Kennel, "A finite-set model predictive position controller for the permanent magnet synchronous motor," in 2013 IEEE International Symposium on Sensorless Control for Electrical Drives and Predictive Control of Electrical Drives and Power Electronics (SLED/PRECEDE). IEEE, oct 2013, pp. 1-7.

[19] A. Formentini, A. Trentin, M. Marchesoni, P. Zanchetta, and P. Wheeler, "Speed Finite Control Set Model Predictive Control of a PMSM Fed by Matrix Converter," IEEE Transactions on Industrial Electronics, vol. 62, no. 11, pp. 6786-6796, nov 2015.

[20] E. Fuentes, C. Silva, and R. Kennel, "MPC Implementation of a QuasiTime-Optimal Speed Control for a PMSM Drive, with Inner ModulatedFS-MPC Torque Control," IEEE Transactions on Industrial Electronics, vol. PP, no. 99, pp. 1-1, 2016.

[21] A. Darba, F. De Belie, P. D'haese, and J. A. Melkebeek, "Improved Dynamic Behavior in BLDC Drives Using Model Predictive Speed and Current Control," IEEE Transactions on Industrial Electronics, vol. 63, no. 2, pp. 728-740, feb 2016.

[22] C. A. Rojas, J. Rodriguez, F. Villarroel, J. R. Espinoza, C. A. Silva, and M. Trincado, "Predictive Torque and Flux Control Without Weighting Factors," IEEE Transactions on Industrial Electronics, vol. 60, no. 2, pp. 681-690, Feb. 2013.

[23] C. A. Silva and J. I. Yuz, "On sampled-data models for model predictive control," in Proc. IECON 2010 - 36th Annual Conf. IEEE Ind. Electron. Soc., 2010, pp. 2966-2971.

[24] C. Garcia, J. Rodriguez, C. Silva, C. Rojas, P. Zanchetta, and H. AbuRub, "Cascaded predictive speed control," in IECON 2014 - 40th Annual Conference of the IEEE Industrial Electronics Society. IEEE, oct 2014, pp. 3824-3830. 